\title{
Crisis de la globalización neoliberal y mercados de trabajo en Andalucía (España)
}

\author{
The crisis of neoliberal globalization \\ and labor markets in Andalusia (Spain)
}

Inmaculada Caravaca

Gema González-Romero

\begin{abstract}
Resumen
Las profundas transformaciones de las estructuras económicas, laborales, sociales e institucionales que se venían produciendo desde finales del siglo XX se han acelerado, profundizado y complejizado durante la última década al generarse una crisis de excepcional calado que, aunque empezó siendo financiera, ha ido evolucionado hasta convertirse en sistémica. Dicha crisis, además de poner en evidencia las fragilidades del sistema está provocando nuevas desigualdades socioeconómicas y territoriales. El objetivo de este artículo es analizar los efectos de la crisis en los mercados de trabajo de las ciudades de Andalucía de más de 20.000 habitantes, intentando detectar si se han producido alteraciones en el modelo territorial de esta región, considerada periférica tanto en el ámbito español como en el europeo.
\end{abstract}

Palabras clave: crisis, globalización neoliberal, mercados de trabajo, ciudades, Andalucía.

\begin{abstract}
The profound changes in economic, labor, social and institutional structures that have been occurring since the late 20th century have become faster, deeper and more complex over the last decade, as a crisis of exceptional depth has been generated. Although it began as a financial crisis, it has evolved to become systemic. This crisis, in addition to exposing the frailties of the system, is causing new socioeconomic and territorial inequalities. The aim of this paper is to analyze the effects of the crisis on labor markets of the cities of Andalusia that have more than 20,000 inhabitants, trying to detect whether there have been changes in the territorial model of this region, which is considered peripheral both in the Spanish and European spheres.
\end{abstract}

Keywords: crisis; neoliberal globalization; labor markets; cities; Andalusia. 
"La utopía industrialista nos prometía que el desarrollo de las fuerzas productivas y la expansión de la esfera económica iban a liberar a la humanidad de la escasez, de la injusticia y del malestar...De esta utopía no queda nada. Esto no quiere decir que todo sea ahora vano y que sólo nos quede someternos al curso de las cosas. Esto quiere decir que es preciso cambiar de utopía; porque mientras permanezcamos prisioneros de lo que se viene abajo, seguiremos siendo incapaces de percibir el potencial de liberación que la actual mutación contiene".

(Andre Gorz: Metamorfosis del trabajo)

\section{Introducción}

Las profundas transformaciones de las estructuras económicas, laborales, sociales e institucionales que se venían produciendo desde finales del siglo XX se han acelerado, profundizado y complejizado durante la última década al generarse una crisis de excepcional calado que, aunque empezó siendo financiera, ha ido evolucionado hasta convertirse en sistémica e incluso en civilizatoria al afectar a la economía en su conjunto, al mercado laboral, al medio ambiente, a las instituciones, a las políticas y a los valores morales y éticos. De este modo, a las perturbaciones asociadas al advenimiento de la sociedad informacional (Castells, 1995 y 1996), la globalización económica (Veltz, 1996; Wackerman, 2011), y la hegemonía alcanzada por la ideología neoliberal (Laval-Dardot, 2013), es necesario añadir los graves impactos generados por la crisis que, además de poner en evidencia las fragilidades del sistema y hacer aflorar sus contradicciones, está provocando nuevas desigualdades socioeconómicas y territoriales (Fernández Durán, 2011; Sassen, 2015).
En efecto, la crisis sistémica iniciada hace ya casi una década, ha provocado una serie de impactos asociados tanto a la forma en que se ha llevado a cabo el proceso de globalización como a los cambios experimentados por el modelo de funcionamiento económico desde finales del pasado siglo. Aunque son múltiples las causas que explican sus orígenes, destacan especialmente dos: la aplicación de estrategias de desregulación económica y laboral, estrechamente asociadas a la llamada ideología neoliberal, y el proceso de financiarización de la economía, sustentada en la utilización de productos financieros muy sofisticados, opacos y de alto riesgo. Tales estrategias han propiciado una fuerte acumulación de capital financiero, en buena parte especulativo, mientras iban quedando en un lugar secundario las actividades directamente productivas (Etxezarreta, 2009; Boccara-Le Héron-Plihon, 2012; Lordon, 2012).

Los efectos de esta profunda crisis han sido devastadores, sobre todo en aquellos países en los que el modelo económico se había sustentado en un desmedido crecimiento del sector inmobiliario (Naredo, 2009 y 2010; Romero, 2010; Burriel, 2011; Rodríguez López, 
2011). Entre los impactos que ha venido generando, destaca con mucho la escandalosa destrucción de puestos de trabajo, pero también la creciente precarización del empleo, que contribuye a fragmentar los mercados de trabajo y, en consecuencia, a acentuar las desigualdades económicas, sociales y territoriales (Intermon Oxfam, 2012; Oxfam Intermon, 2013).

Pero no hay que olvidar que si desde la perspectiva social se está produciendo un aumento de las desigualdades, desde la territorial se están generando transformaciones asociadas a los modelos de acumulación de capital y a la función que ejerce cada ámbito territorial en el conjunto del sistema. No puede extrañar, en consecuencia, que los efectos indeseados de la crisis se hayan multiplicado considerablemente en aquellos países en los que la burbuja financiera que la desencadenó estaba asociada a otra inmobiliaria que, al estallar, contribuyó a multiplicar la pérdida de empleos tanto en el sector de la construcción, como en aquellos otros que, directa o indirectamente, estaban vinculados a él. De este modo, y tal y como había ocurrido en ocasiones anteriores, el sector de las construcción adoptó un rol estratégico como articulador entre las actividades financieras y la economía real, contribuyendo a potenciar la crisis (Daher, 2013). Se pone así en evidencia la complejidad de una crisis que, aunque puede considerarse global, ya que afecta al conjunto del sistema, no es uniforme, puesto que incide en los territorios con distintas formas e intensidades.

En este último sentido, hay que llamar la atención acerca del hecho de que mientras son muy numerosas las investigaciones realizadas sobre las causas de la crisis y las transformaciones estructurales que provoca, son aún insuficientes las que se ocupan de los cambios territoriales que está generando (Corpataux-Crervoisier-Theurillat, 2009; Méndez, 2014; Alberto-Sánchez, 2014). En tal contexto, son especialmente necesarios aquellos análisis que centran la atención en la relación crisis/empleo/territorio.

Como es sabido, las ciudades concentran la mayor parte de la población así como los procesos de producción, distribución e intercambio de información, conocimientos, productos, bienes y servicios. No es de extrañar, por consiguiente, que los ámbitos urbanos se estén viendo especialmente afectados por la crisis; lo que se pone en evidencia, por ejemplo, en el informe publicado por la Unión Europea (Soto, 2010), y en las investigaciones realizadas en las ciudades británicas (Lee-Morris-Jones, 2009), norteamericanas (Paulais, 2009) y españolas (Méndez, 2013a, 2013b; AlbertoSánchez, 2014; Méndez-Abad-Echaves, 2015).

En relación con los procesos de desarrollo territorial - entendido éste desde la triple perspectiva económica, social y ambiental los sistemas urbanos requieren una especial atención, puesto que tanto la distribución jerárquica como la espacial de las ciudades pueden contribuir a potenciar o a frenar los procesos de desarrollo (Capel, 2003). Junto a lo anterior, no hay que olvidar el papel que ejercen las ciudades medias en dichos procesos pues, al actuar como nodos de articulación entre las grandes aglomeraciones urbanas y los ámbitos rurales, pueden generar efectos multiplicadores en los territorios (CamagniSalone, 1993; Bellet-Llop, 2000, 2004; Capel, 2003). Es por ello por lo que desde la Unión 
Europea se han venido elaborando informes que, sosteniendo estas tesis, plantean algunas propuestas de actuación: Estrategia Territorial Europea (1999), Programa de Estudios sobre Planificación Espacial Europea (2000), Informes sobre la Cohesión Económica y Social (1999, 2000, 2004). Los sistemas urbanos y las ciudades que los conforman son, pues, escenarios idóneos para observar los efectos de la crisis, y su conocimiento puede ayudar a diseñar estrategias específicas de actuación con las que reaccionar a ella propiciando, a su vez, modelos alternativos de desarrollo.

Con este marco general de referencia, el objetivo de este artículo es analizar los efectos de la crisis en los mercados de trabajo de las ciudades de Andalucía con más de 20.000 habitantes, intentando detectar si se han producido alteraciones, y de qué índole, en el modelo territorial de la región. Se trata, pues, de objetivos de especial interés para observar la relación entre crisis y territorio, sobre todo teniendo en cuenta que España es uno de los países europeos que ha encabezado el ranking de destrucción de empleo y que la región objeto de estudio, considerada periférica tanto en el ámbito español como en el europeo, es precisamente una de las más afectadas por la crisis.

Se parte de la hipótesis de que la incidencia de la crisis en los mercados urbanos de trabajo depende de la forma en que se inserten las ciudades en el sistema urbano regional, de los recursos con que cuenten y su forma de activarlos, de sus trayectorias históricas, de sus estructuras económicas, de las actitudes más o menos proactivas de sus agentes locales para impulsar procesos de desarrollo y de la capacidad de reacción que éstos tengan ante circunstancias adversas (Méndez, 2002; Martin-Simmie, 2008; Salon-Albertos, 2009). Para llevar a cabo el análisis se plantean las siguientes preguntas de investigación: ¿Cómo están incidiendo la globalización neoliberal y la crisis en los mercados de trabajo? ¿Por qué perjudica más la crisis a unos territorios que a otros, ya se trate de países, regiones o ciudades? ¿Cómo afecta la crisis al empleo en una región caracterizada por su incapacidad histórica para generar suficientes puestos de trabajo? ¿Se están produciendo cambios, y de qué tipo, en el sistema urbano andaluz? ¿Están aumentando los desequilibrios interurbanos en Andalucía?

Los principales indicadores utilizados para la realización de esta investigación son el empleo y el paro, ${ }^{1}$ considerados básicos para conocer los comportamientos de los mercados de trabajo $y$, en consecuencia, especialmente ilustrativos de los impactos generados por la crisis. Aunque se utiliza alguna información complementaria, la mayor parte procede del Registro de la Tesorería General de la Seguridad Social y del Servicio Público de Empleo Estatal. El periodo de referencia se sitúa entre el año 2006, que antecede a la crisis, y el 2014 que es el último para el que se cuenta con información disponible. ${ }^{2}$

Desde la perspectiva geográfica que aquí se propone, es necesario enfatizar acerca del ámbito territorial en el que se localizan las ciudades y del lugar que éstas ocupan en el sistema urbano regional. En el caso de Andalucía, la región cuenta con un sistema urbano equilibrado no sólo desde la perspectiva jerárquica sino también desde la territorial, estando las ciudades 
muy equitativamente repartidas por el territorio regional; no obstante, se localizan fundamentalmente a lo largo de la costa y del Valle del Guadalquivir - que separa los macizos montañosos de Sierra Morena (al norte) y las Cordilleras Béticas (al sur) - así como en el conjunto de depresiones situadas entre estas últimas cordilleras.

Para llevar a cabo el análisis se han tenido en cuenta las unidades territoriales establecidas en el Plan de Ordenación Territorial de Andalucía que distingue, por una parte, las nueve aglomeraciones urbanas, que son los nodos esenciales que estructuran el territorio andaluz; $y$, por otra, las ciudades medias, que actúan como importantes eslabones que enlazan a las aglomeraciones con los ámbitos rurales (Consejería de Obras Públicas y Transportes de la Junta de Andalucía, 2007) (Figura 1).

Figura 1 - Modelo territorial de Andalucía

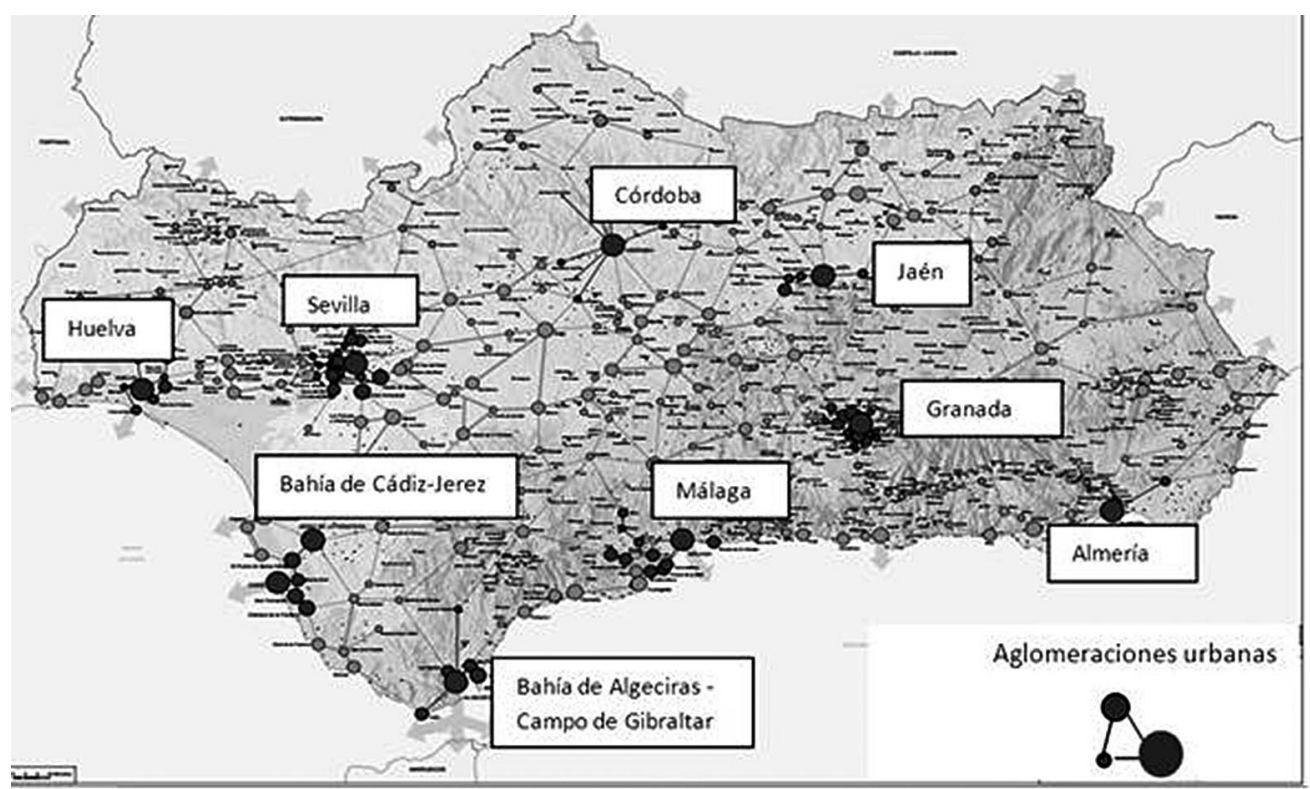

Fuente: Junta de Andalucía, Plan de Ordenación del Territorio de Andalucía (2007). 
El artículo se estructura en seis epígrafes. Tras esta introducción, se reflexiona acerca de la relación existente entre globalización neoliberal, crisis y empleo (epígrafe segundo). En el epígrafe tercero se contextualiza la situación de Andalucía en España y la Unión Europea, para después centrar la atención en los efectos de la crisis en las ciudades tanto en lo que respecta al empleo (epígrafe cuarto) como al paro (epígrafe quinto). Por último, se incluyen algunas consideraciones y reflexiones a modo de conclusión.

\section{Globalización neoliberal, crisis y mercado de trabajo}

La historia del capitalismo ha ido evolucionando apoyándose en crisis periódicas de diferente consistencia e intensidad, pero manteniendo siempre los principios básicos que sustentan el sistema. Si bien es cierto que buena parte de estas crisis han sido coyunturales y han afectado sólo a determinados sectores de actividad y ámbitos territoriales, se han producido también otras que, al afectar al conjunto del sistema, han supuesto verdaderas rupturas y cambios estructurales que han conformado diferentes ciclos en la evolución del capitalismo.

Reviste particular interés la crisis iniciada en los años setenta del pasado siglo, asociada al desarrollo de la llamada sociedad informacional y a un proceso de mundialización económica hasta entonces sin precedentes. No hay que olvidar que algunas de las lógicas económicas y socio-laborales surgidas en el citado periodo siguen estando en buena parte vigentes $y$, por tanto, resultan fundamentales para interpretar los cambios que se han venido produciendo y que han dado lugar a la crisis actual (Caravaca, 2014). Como dice Mayor Zaragoza, es durante las dos últimas décadas del siglo XX cuando hay que situar "el gran antecedente de la crisis actual: los valores democráticos, los principios éticos se sustituyen por el mercado" (Mayor Zaragoza, 2011, p. 32). También Morin enfatiza el hecho de que la crisis que ahora se padece tiene sus raíces en "la explosión de un capitalismo planetario, sin frenos desde la década de 1990, que ha amplificado todos los aspectos negativos del desarrollo (económico)" (Morin, 2011, p. 26).

Como pretende sintetizar la Figura 2 , es precisamente a partir de las citadas décadas cuando, junto a la Revolución Tecnológica informacional y la globalización de la economía, empieza a extenderse una ideología neoliberal que se traduce en la aplicación de estrategias de privatización y de desregulación hasta el punto de que "la política monetaria se utiliza para luchar contra la inflación y no para sostener la inversión (mientras que) la moderación salarial se convierte en uno de los objetivos centrales de las políticas económicas" (Sterdyniak, 2012, pp. 30-31). De esta forma, "la característica principal del capitalismo mundializado desde comienzos de los años ochenta es la bajada de la parte salarial, esto es, de la parte del PIB correspondiente a los asalariados" (Husson, 2009 , p. 7). Como consecuencia de todo lo anterior, la precariedad empieza a convertirse en un rasgo definitorio del funcionamiento de unos mercados de trabajo que, no sólo son incapaces de generar suficiente número de 
Figura 2 - Principales causas y consecuencias de la crisis

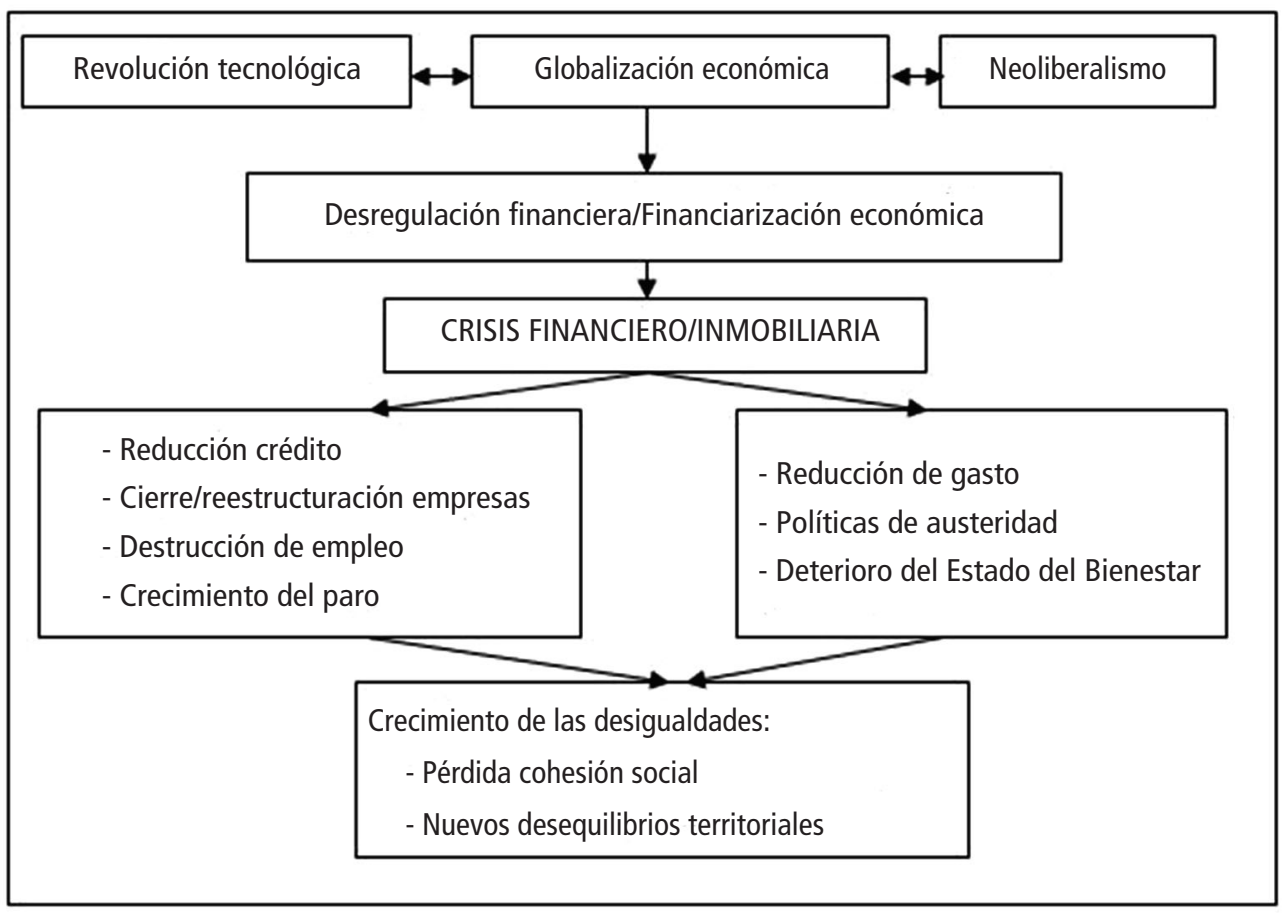

Fuente: Elaboración propia.

empleos y de que éstos sean de cierta calidad, sino también de frenar su continua destrucción.

Por su parte, la Revolución Tecnológica ha provocado una creciente fragmentación de los mercados de trabajo pues, mientras que un número elevado de personas son expulsadas de los mismos o mantenidas en ellos de forma precaria, otro grupo trabaja cada vez más recibiendo a cambio crecientes ingresos. Efectivamente, al informatizar determinadas tareas "se produce más y mejor con una fracción decreciente de los efectivos empleados con anterioridad y se ofrece a ciertos trabajadores de élite unos privilegios que tienen como contrapartida el paro, la precariedad en el empleo, la descualificación y la inseguridad del mayor número de trabajadores" (Gorz, 1995, p. 93).

A su vez, "la distribución desigual del trabajo de la esfera económica y el desigual reparto del tiempo que libera la innovación técnica conducen a que unos puedan comprar un suplemento de tiempo libre a otros y que estos últimos no tengan más remedio que ponerse al servicio de los primeros"..." Renace así una clase servil que la industrialización, después de la II Guerra Mundial, había abolido". Resulta, además, éticamente intolerable que algunos gobiernos $y$, lo que es peor, ciertos sindicatos, legitimen y favorezcan "esta formidable regresión social con el pretexto de que permite 'crear empleos', 
e incluso de que los servidores aumenten el tiempo que sus amos pueden dedicar a unas actividades económicamente muy productivas" (Gorz, 1995, pp. 17-18).

En este contexto, la explosión de la burbuja financiero-inmobiliaria que da origen a la crisis iniciada hace ya casi una década provoca una pérdida de empleos sin precedentes, que no sólo no se palia con la aplicación de las medidas que, supuestamente, tenían por objeto controlar la crisis sino que, por el contrario, éstas generan nuevas pérdidas. En efecto, llama especialmente la atención el fuerte crecimiento del paro experimentado en buena parte de los países desarrollados, y especialmente en los europeos, asociado primero a la caída del sector de la construcción y a la reestructuración del sector financiero, y después a la aplicación de políticas neoliberales de austeridad que reducen los empleos públicos a la vez que privatizan buena parte de los servicios sociales con el consiguiente deterioro del Estado del Bienestar (Torres López, 2011; Méndez, 2013a).

Ante una situación como la descrita, produce cuanto menos desconcierto que, mientras las cifras de desempleo están llegando a alcanzar valores insostenibles en un buen número de países el objetivo de creación de empleo haya ido perdiendo peso frente al de la consecución de beneficios, que se convierte para las empresas en absolutamente prioritario. No puede extrañar, por consiguiente, que algunos interpreten que el desempleo se ha convertido en un instrumento útil para legitimar determinadas políticas, "no sólo porque ha permitido argumentar que se llevaban a cabo con la intención de que un mercado de trabajo más flexible garantizase la creación de empleo, sino también porque ha desactivado parcialmente la propia capacidad de respuesta de los asalariados" (Álvarez Peralta, Luengo Escalonilla, Uxó González, 2013, p. 229). Se ha producido así un reforzamiento "del control político de las élites capitalistas sobre las fuerzas de trabajo de los países centrales, así como sobre la mayor parte de las economías de los países del Sur (de Europa)" (López-Rodríguez, 2010, pp. 47-48).

Tan deplorable situación convierte la creación de empleos, suficientes en número y con la debida calidad, en uno de los principales retos a los que las sociedades actuales tienen que hacer frente.

\section{Andalucía en el contexto europeo y español}

Es un hecho constatado que la crisis iniciada en 2008 está afectando intensamente a los países de la Unión Europea. El principal factor que ayuda a entender esta situación es la fuerte integración de sus mercados - más acusada aún en los que conforman la Unión Monetaria - que ha contribuido a facilitar el contagio entre unos y otros países (Daher, 2004). De este modo, la eurozona aún está lejos de haber superado la crisis y sus problemas sociales "no sólo son combatidos de una manera absolutamente insuficiente, sino que incluso se agravan cada vez más, sobre todo el de las altísimas tasas de desempleo" (Busch, 2014, p. 28).

Frente a lo que cabría esperar, la reacción institucional de la Unión Europea está siendo lenta y muy desafortunada. 
Desde la perspectiva socioeconómica están aumentando las disparidades en la distribución de la renta sin que se implementen medidas que contribuyan a recuperar los anteriores niveles de cohesión social, de tal modo que se ha producido un "ahondamiento de las desigualdades que es proporcional al grado de avance de las políticas neoliberales" (Husson, 2009, p. 57),

Estas crecientes desigualdades se observan también desde la perspectiva territorial, pues, "la organización de la zona euro, que impone políticas macroeconómicas semejantes a países que se encuentran en situaciones diferentes, ha incrementado las divergencias entre los Estados miembros" (VVAA, 2012, p. 51). Así, "España, Portugal y Grecia han sido penalizados con una pérdida de producción de entre un 5 y un $10 \%$ del PIB, Francia con una pérdida del $6 \%$, mientras Alemania, por el contrario, se beneficiaba de un efecto favorable equivalente al $8 \%$ de su PIB" (Dévoluy et al., 2012, p. 56). Siendo esto así, no puede extrañar que se haya producido una fuerte destrucción de empleo en los países del sur de Europa (Rocha, 2012; Rocha-Aragón, 2012; Rocha SánchezNegueruela Cortés, 2014).

En España la pérdida de puestos de trabajo desde que se inició la crisis ha sido especialmente significativa, habiéndose destruido 3.769.500 de puestos de trabajo entre los años 2006 y 2014 (Encuesta de Población Activa, INE). La cifra es más alarmante aún si se analizan las tasas de paro, pues en 2014 , con el $24,4 \%$, únicamente se sitúa por debajo de Grecia (25,9\%), encontrándose muy alejada de la media europea $(9,8 \%)$ (Eusrostat). Si, por una parte, resulta llamativo el elevado número de empleos que se han venido destruyendo, y las altas tasas de paro alcanzadas, por otra, destaca así mismo la creciente precariedad de los puestos de trabajo que se están creando (ÁlvarezLuengo-Uxó, 2013). Se puede entender así que el mercado de trabajo español sea uno de los más fragmentados y de los que peor funcionan del ámbito comunitario (López y Rodríguez, 2010; Rocha e Aragón, 2012; Rocha, Sánchez y Negueruela Cortés, 2014).

Pero no hay que olvidar que esto ocurre en un país cuya falta de capacidad para generar empleo, incluso en periodos de fuerte crecimiento económico, se ha venido considerando desde hace décadas uno de los rasgos estructurales de su economía. Como se ha señalado repetidamente al respecto, “la destrucción de empleo agrícola que ha conocido la economía española, especialmente intensificada en los años sesenta, se conjuga con un comportamiento de los sectores de la industria y la construcción que oscila en torno a una línea tendencial de valor cero, de modo que los empleos que se generan en las fases expansivas del ciclo se destruyen en las depresivas" (Delgado Cabeza-Sánchez Fernández, 1999, p. 49).

Esta tendencia estructural se distribuye de forma muy desigual entre las regiones que conforman el estado español, lo que hay que poner en relación con las funciones que desempeña cada territorio en la división espacial del trabajo. En efecto, "las economías periféricas, como consecuencia de su forma específica de integración, ven distanciarse sus condiciones de las de los territorios hegemónicos...que son los capaces de imponer su política económica cuando 
el estado keynesiano del bienestar ha sido sustituido por el estado schumpeteriano de la eficacia" (Delgado Cabeza-Sánchez Fernández, 1999, p. 57).

Andalucía es precisamente una de las regiones españolas menos desarrolladas y más dependientes; su débil industrialización y su especialización en actividades maduras de escasa demanda, baja intensidad tecnológica y basadas en el uso de trabajo poco cualificado han condicionado su evolución económica adecuándola a las exigencias de acumulación de regiones centrales, como Cataluña y el País Vasco (Delgado Cabeza, 1981, 1996 y 2006). Durante la etapa desarrollista de los años sesenta del pasado siglo una parte significativa de la población andaluza se vio obligada a emigrar tanto hacia otras regiones españolas como hacia algunos países europeos, ya que el débil crecimiento experimentado entonces por la industria y los servicios no fue capaz de generar un número de empleos suficiente para absorber a los efectivos que el proceso de desagrarización estaba expulsando del campo. Posteriormente, la crisis de los años setenta y el proceso de reestructuración productiva de inicios de los ochenta - que coincidió además con la vuelta de muchos emigrantes y la progresiva incorporación de la mujer al trabajo - no hicieron sino acentuar la ya tradicional incapacidad de la economía andaluza para crear puestos de trabajo. Desde entonces, la región ha evolucionado a través de fuertes contrastes, de tal modo que a pesar de que en las coyunturas expansivas se han observado comportamientos más dinámicos que los de la media española, en las etapas recesivas éstos han sido más negativos (Castells-Hall, 1992; Aurioles, 1995).

La Figura 3 contribuye a poner en evidencia algunas de las diferencias estructurales existentes entre los mercados de trabajo de Andalucía, España y la Unión Europea, siendo muy evidentes las desiguales trayectorias de las curvas evolutivas de las tasas de empleo correspondientes a España y Andalucía respecto a la Unión Europea, así como las diferencias cuantitativas existentes, ya de partida y ampliadas además a lo largo del tiempo, entre España en su conjunto y Andalucía.

Especialmente ilustrativas del grave problema que supone la falta de empleo para esta región son sus tasas de paro que, frente a los valores medios del $11 \%$ de la Unión Europea en 2013 (Eurostat) o del sorprendente 26\% de España, llegan a alcanzar el $36 \%$ en Andalucía ese mismo año (Encuesta de Población Activa, INE). Hay que tener en cuenta, además, que aun cuando la evolución de la curva es positiva a partir de 2013, la tasa de paro en 2015 sigue alcanzando cifras alarmantes, tanto en esta región (34\%) como en España (23\%) (Figura 4). A ello hay que añadir que el empleo creado desde entonces es temporal y precario, de tal forma que su crecimiento se corresponde en buena parte a contratos temporales y salarios mucho más bajos y claramente insuficientes (Estadística de contratos, Servicio Público de Empleo Estatal). 
Figura 3 - Evolución de las tasas de empleo 3 en Andalucía, España y la Unión Europea

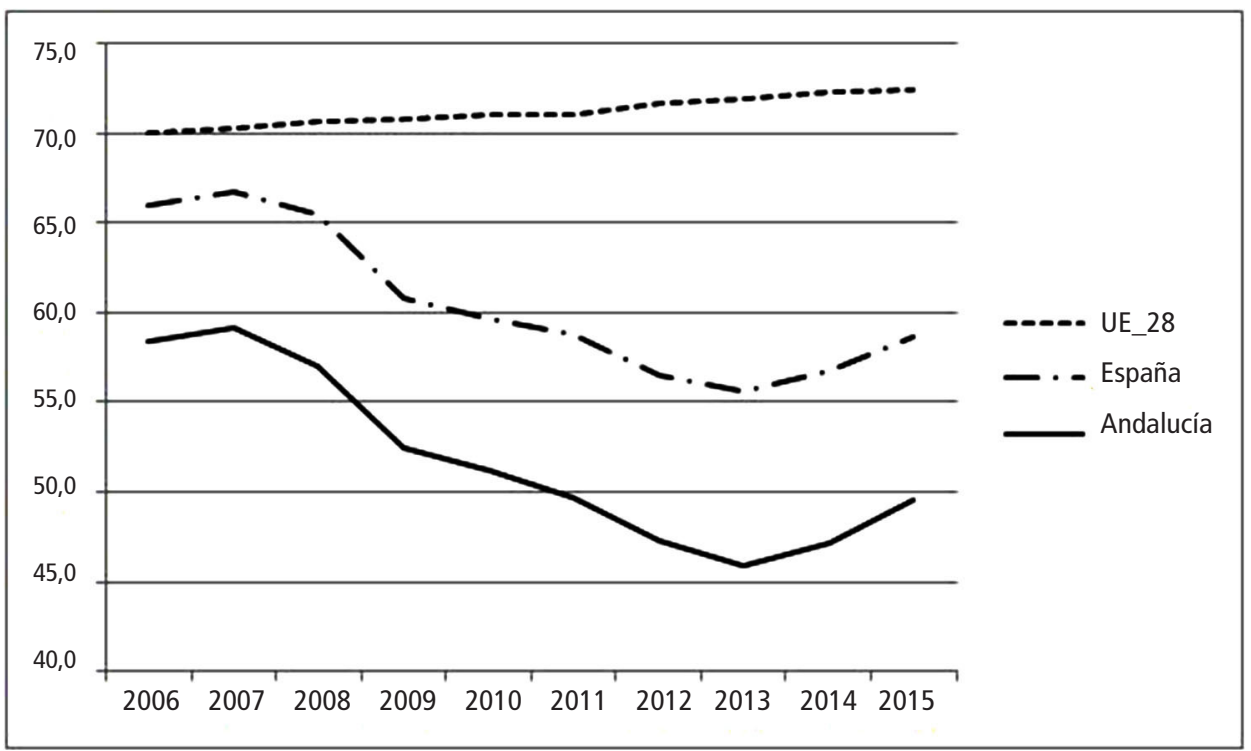

Fuentes: Eurostat, Instituto Nacional de Estadística.

Figura 4 - Evolución de las tasas de paro en Andalucía, España y la Unión Europea

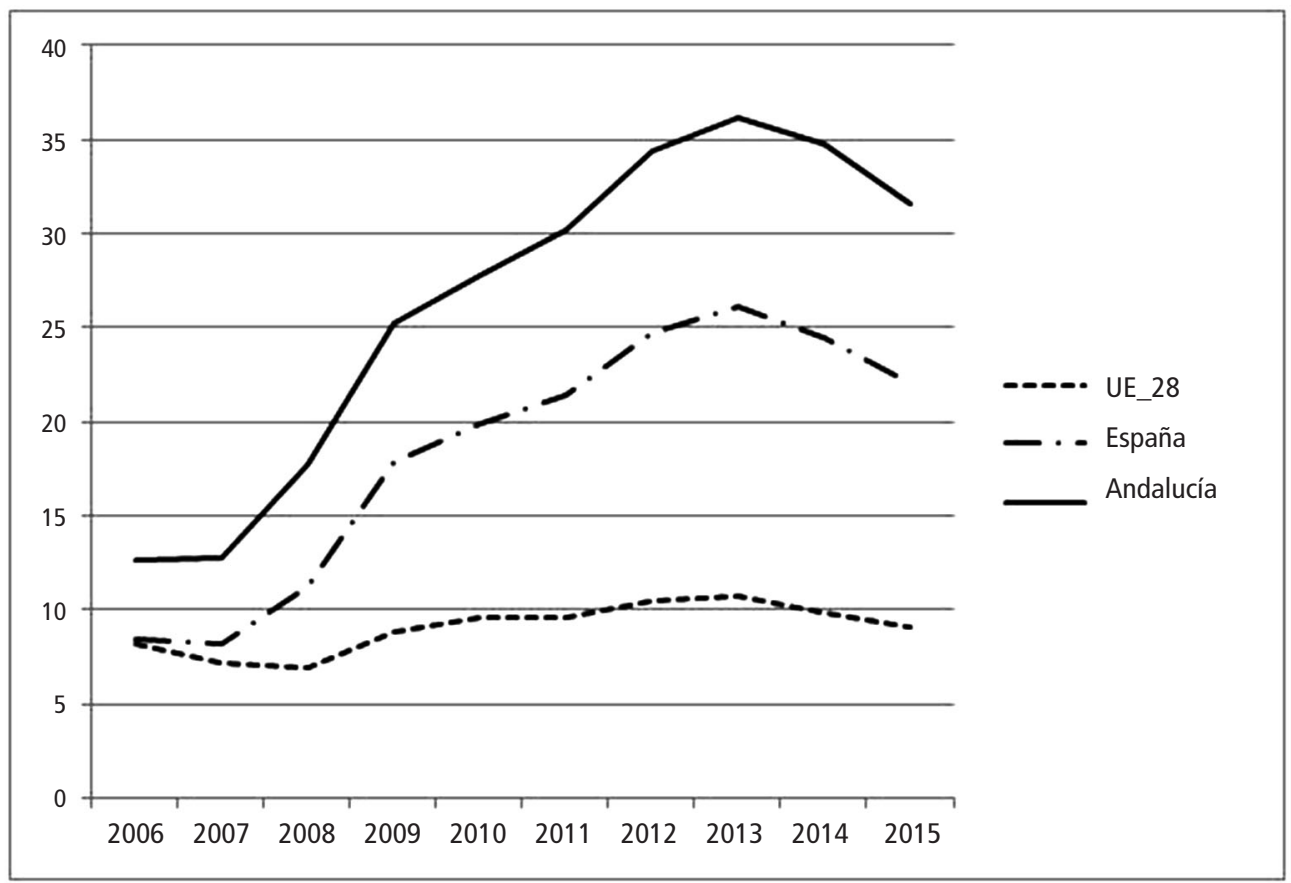

Fuentes: Eurostat, Instituto Nacional de Estadística 
Los problemas relacionados con la destrucción de empleos provocada por la crisis financiero - inmobiliaria se han visto agravados por las políticas de austeridad impuestas por las instituciones europeas a aquellos países más castigados por la crisis. En este último sentido, resulta escandaloso que, mientras se ha transferido una enorme cantidad de dinero público al sector financiero a través del denominado rescate bancario - lo que se ha traducido en un importante crecimiento de la deuda pública de los países concernidos y supone una socialización de las pérdidas generadas por las instituciones bancarias - se flexibiliza el mercado de trabajo y se precariza el empleo, además de recortar sustancialmente las partidas presupuestarias vinculadas a gastos sociales básicos entre los que se incluyen las prestaciones por desempleo. Se están perdiendo así importantes conquistas sociales mientras que "en lugar de hacer frente a todos los daños y problemas para poner remedio a las causas que los han provocado, las autoridades se han doblegado ante los poderes que ocasionaron la crisis y éstos han salido de ella mucho más reforzados" (Torres López, 2011, p. 59).

\section{La evolución del empleo en las ciudades de Andalucía}

Las formas en que está incidiendo la crisis en los distintos territorios dependen, por una parte, del grado de vulnerabilidad de cada ámbito y por otra, de las capacidades que muestran los agentes e instituciones locales para desarrollar estrategias con las que enfrentar y superar los problemas y activar nuevos procesos de desarrollo. En consecuencia, los cambios estructurales que se vienen produciendo con la crisis financieroinmobiliaria están afectando en mayor medida a aquellas ciudades que son más vulnerables, tanto por sus características demográficas, económicas, sociales y territoriales como por las actitudes más o menos reactivas 0 proactivas de sus agentes locales.

Según puede observarse en la Tabla 1, sigue existiendo un desequilibrio económico entre los municipios que conforman el sistema territorial andaluz, puesto que sólo en los que superan los 100.000 habitantes el peso relativo de las actividades económicas, medido a través del empleo que éstas generan, es mayor que el de la población. Los cambios que se han ido produciendo a lo largo del tiempo muestran claramente distintos grados de incidencia de la crisis según tamaño poblacional. Investigaciones precedentes indicaron que, durante la etapa económicamente expansiva (2000-2006), el crecimiento más significativo se produjo en aquellos municipios cuya población oscilaba entre los 20.000 y 100.000 habitantes, poniéndose en evidencia la positiva evolución experimentada por las actividades económicas en ciudades clasificadas como medias cuya presencia es clave para el equilibrio del sistema urbano andaluz y, en consecuencia, para los procesos de desarrollo territorial (Caravaca, González, Mendoza y Silva, 2009). Como contrapunto a lo anterior, durante la etapa recesiva (2006-2014) los comportamientos de los distintos tamaños municipales han seguido la tendencia contraria pues, son precisamente las ciudades de menos de 100.000 habitantes 
Tabla 1 - Empleos por tamaños municipales, 2006- 2014

\begin{tabular}{l|c|c|c|c|c|c}
\hline \multicolumn{1}{c|}{ Tamaño municipal } & $\begin{array}{c}\text { Número de } \\
\text { municipios }\end{array}$ & \multicolumn{2}{c|}{ Población 2014 } & \multicolumn{2}{c}{ Empleos 2014 } & $\begin{array}{c}\text { Empleos } \\
\mathbf{2 0 0 6 - 2 0 1 4} \\
(2006=100)\end{array}$ \\
\hline $20.001-50.000$ & 52 & 1.427 .241 & $17 \%$ & 404.291 & $15 \%$ & $-12 \%$ \\
\hline $50.001-100.000$ & 17 & 1.253 .720 & $15 \%$ & 303.386 & $11 \%$ & $-16 \%$ \\
\hline $100.001-250.000$ & 9 & 1.177 .387 & $14 \%$ & 428.317 & $16 \%$ & $-13 \%$ \\
\hline$>250.000$ & 3 & 1.829 .170 & $22 \%$ & 750.252 & $28 \%$ & $-11 \%$ \\
\hline Total municipios urbanos $>20.000 \mathrm{~h}$ & 81 & 5.687 .518 & $68 \%$ & 1.886 .246 & $71 \%$ & $-12 \%$ \\
\hline Andalucía & 771 & 8.402 .305 & $100 \%$ & 2.647 .537 & $100 \%$ & $-12 \%$ \\
\hline
\end{tabular}

Fuente: Tesorería General de la Seguridad Social; Padrón Municipal de Habitantes, INE. Elaboración propia.

las que han visto reducir en mayor medida sus empleos, mientras que las que se sitúan en los primeros puestos de la jerarquía urbana son las que mejor han resistido.

Si se centra la atención en las aglomeraciones urbanas (Tabla 2) se observan diferencias significativas entre las mismas, constatándose cómo la crisis se ha cebado justamente con aquellas que venían padeciendo situaciones muy graves de desempleo ya antes de que ésta se iniciara, coincidiendo con ámbitos con una actividad industrial, asociada a la fase fordista, en constante declive (Bahía de Cádiz-Jerez y Bahía de Algeciras-Campo de Gibraltar). A diferencia de ello, las que se han visto en menor medida afectadas son las que cuentan con municipios donde se conjuga la presencia de un importante tejido industrial con una destacada actividad agrícola (Huelva y Jaén). Por su parte, las aglomeraciones de mayor tamaño poblacional (Málaga y Sevilla) se encuentran en una situación intermedia.

Para profundizar en el conocimiento de los impactos territoriales generados por la crisis se ha elaborado el mapa de la Figura 5 que recoge la evolución experimentada por el número de empleos en los municipios urbanos mayores de 20.000 habitantes entre 2006 y 2014. Tal y como puede comprobarse, la situación no puede ser más negativa para el conjunto de estos municipios puesto que únicamente ocho de ellos han conocido un incremento en sus empleos. Si en un primer momento la crisis se vinculó a la actividad inmobiliaria, siendo sus efectos más selectivos territorialmente, con posterioridad al aplicarse las políticas de ajuste económico se generalizaron al conjunto de la región, afectando también a ciudades con una especialización económica menos dependiente de la actividad constructiva. 
Tabla 2 - Evolución del empleo en las aglomeraciones urbanas, 2006- 2014

\begin{tabular}{l|c|c|c}
\hline & Número de municipios & Empleos 2014 & $\begin{array}{c}\text { Empleos 2006-2014 } \\
(2006=100)\end{array}$ \\
\hline Almería & 9 & 97.112 & $-12 \%$ \\
Bahía de Cádiz-Jerez & 6 & 180.979 & $-16 \%$ \\
Bahía de Algeciras- Campo de Gibraltar & 7 & 59.225 & $-20 \%$ \\
Córdoba & 8 & 131.361 & $-11 \%$ \\
Granada & 32 & 181.699 & $-11 \%$ \\
Huelva & 8 & 90.734 & $-9 \%$ \\
Jaén & 14 & 91.353 & $-5 \%$ \\
Málaga & 13 & 288.631 & $-13 \%$ \\
Sevilla & 46 & 508.532 & $-11 \%$ \\
Andalucía & 771 & 2.647 .537 & $-12 \%$ \\
\hline
\end{tabular}

Fuente: Tesorería General de la Seguridad Social, Padrón Municipal de Habitantes, INE. Elaboración propia.

Figura 5 - Evolución del empleo de 2006 a 2014

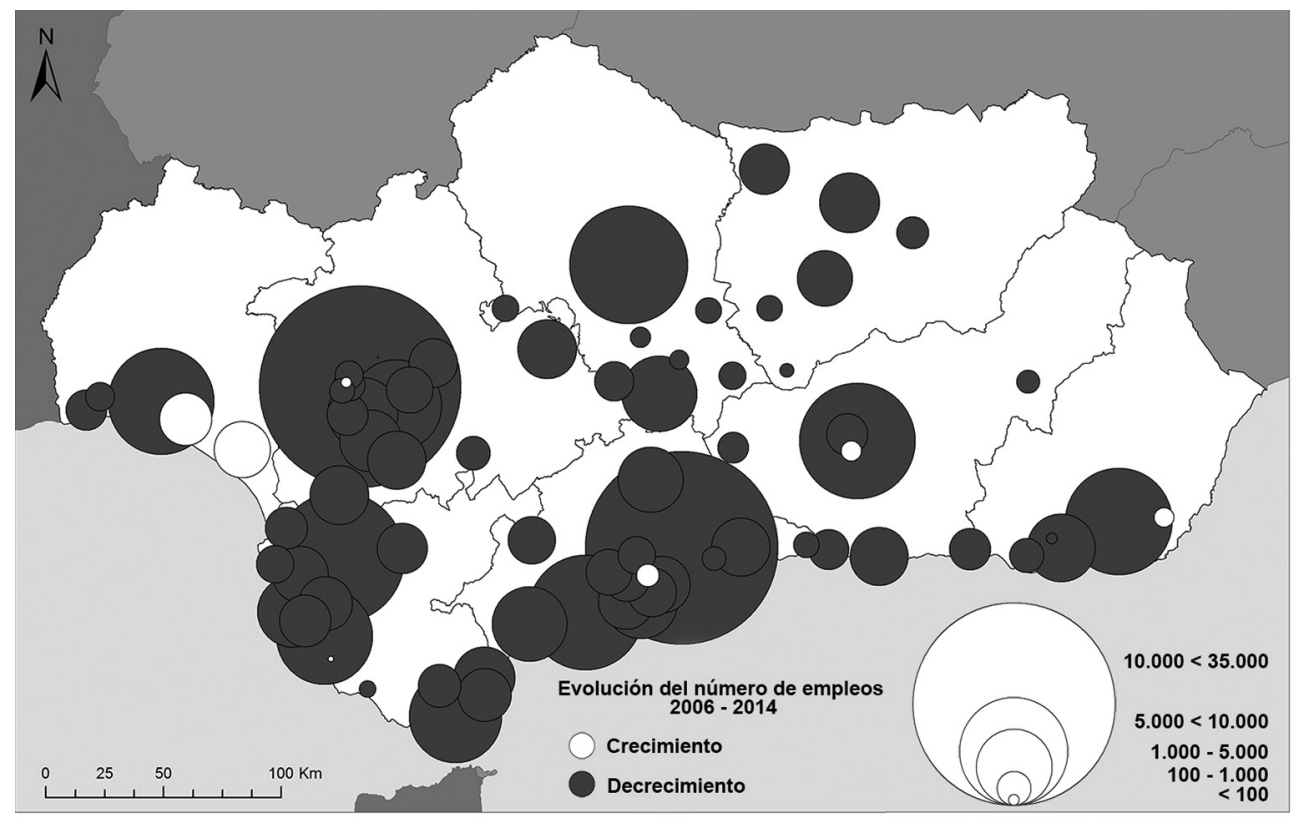

Fuente: Tesorería General de la Seguridad Social. Elaboración propia. 
En el período analizado, los municipios de más de 20.000 habitantes que mejor han resistido a la crisis se corresponden con ciudades medias, la mayoría de ellas litorales con un considerable desarrollo de la agricultura intensiva que combinan con el turismo; es el caso de las situadas en la costa onubense y gaditana, así como las del poniente almeriense, aunque entre las mismas también hay alguna localizadas en aglomeraciones urbanas. A diferencia de las anteriores, la reducción de los empleos se va haciendo evidente en los ámbitos costeros y en la mayoría de las ciudades de las principales aglomeraciones urbanas (Sevilla, Málaga, y bahías de Cádiz y Algeciras).

\section{Crisis y desempleo en las ciudades andaluzas}

El derecho a un trabajo y que éste sea digno está reconocido en la Declaración Universal de Derechos Humanos aprobada el año 1948 (artículo 23) y se afianzó, además, en la Declaración relativa a los principios y derechos fundamentales en el trabajo, firmada en la Conferencia Internacional de la Organización Internacional del Trabajo de 1998. Pese a ello, el desempleo no ha llegado nunca a desaparecer por completo, aunque en su comportamiento se hayan observado siempre notables diferencias entre países, grupos sociales y territorios.

Es precisamente éste el principal problema de Andalucía y durante los últimos años está alcanzando dimensiones verdaderamente escandalosas. Según las cifras de paro del Servicio Público de Empleo Estatal (SEPE), las ciudades objeto de estudio cuentan con 745.530 parados registrados, lo que supone un $72 \%$ del total de Andalucía, porcentaje que supera al de su población (68\%).

Pese a que, como ya se ha señalado, la OIT (Organización Internacional del Trabajo) defiende que todas las personas deben tener los mismos derechos para desarrollar un trabajo, es un hecho comprobado que las oportunidades han sido siempre muy diferentes para distintos grupos sociales. Resulta, además, inquietante que, frente a los avances sociales que se habían venido produciendo con la aplicación de políticas asociadas al Estado del Bienestar, estén creciendo de nuevo las desigualdades con políticas de ajuste que afectan en mayor medida a los colectivos más vulnerables. En la Tabla 3 se recogen las principales diferencias existentes al respecto entre Andalucía y España.

Según el Instituto Nacional de Estadística se consideran parados de larga duración a las personas que, buscando activamente empleo, llevan sin trabajar doce meses consecutivos como mínimo. En España la evolución experimentada por este colectivo está siendo extremadamente preocupante, puesto que afectaba a 3.466.000 personas en el año 2014 (62\% de los parados), lo que supone 7 veces más que en 2006. La magnitud del problema se pone aún más en evidencia si se tiene en cuenta que un $10,4 \%$ de la población activa lleva más de dos años en paro y, por tanto, han agotado el derecho a la prestación por desempleo. La situación se agrava, además, porque aumenta el número de parados que, al sentirse desanimados, dejan de buscar trabajo, llegando hasta el punto de quedar algunos excluidos del sistema. No puede extrañar, por consiguiente, que las instituciones europeas 
Tabla 3 - Colectivos especialmente afectados por el desempleo en España y Andalucía, 2006-2014

\begin{tabular}{l|c|c|c|c}
\hline \multirow{2}{*}{ Colectivos } & $\begin{array}{c}\text { Crecimiento relativo del desempleo } \\
2006-2014\end{array}$ & \multicolumn{3}{c}{ Tasas de paro 2014 $\%$ (200) $\%$} \\
\cline { 2 - 5 } & Andalucía & España & Andalucía & España \\
\cline { 2 - 5 } & +552 & +635 & 62 & 62 \\
Parados de larga duración (+12 meses consecutivos) & +87 & +91 & 61 & 53 \\
Paro juvenil (16<25 años) & +159 & +169 & 37 & 25 \\
Paro mujeres & - & - & 38 & 35 \\
Paro inmigrantes* & +210 & +205 & 35 & 24 \\
\hline Total parados & & & & \\
\hline
\end{tabular}

* La EPA no ofrece datos absolutos sobre el paro de inmigrantes.

Fuente: Encuesta de Población Activa-EPA, INE.

hayan reclamado al gobierno español la aplicación de políticas activas de empleo que afronten este gravísimo problema. En Andalucía los parados de larga duración alcanzan también unas cifras preocupantes, 868.400 parados que representan el $62 \%$ del total en 2014, habiendo sido su incremento respecto a 2006 algo inferior que al del conjunto nacional, aunque no por ello las cifras son menos alarmantes (Tabla 3).

Aunque, como se viene señalando, el desempleo se ha convertido en el principal problema socioeconómico tanto de España como de Andalucía, y resulta especialmente preocupante el que afecta a los menores de veinticinco años. En efecto, en España la población con edades comprendidas entre 16 y 25 que trabaja o busca activamente empleo asciende a un total de 1.599.400 habitantes en 2014 y de ellos, 850.800 buscan empleo sin encontrarlo, lo que supone una tasa de paro del $53 \%$. Las cifras son evidentemente escandalosas e insostenibles, frenan la recuperación económica y ponen en evidencia la vulnerabilidad de este grupo social y el fuerte riesgo a que está sometido. En Andalucía estos valores alcanzan casi el $61 \%$ de ese grupo poblacional, lo que patentiza la extrema gravedad de la situación. Lo preocupante no son sólo los valores alcanzados, sino también la evolución seguida entre 2006 y 2014, pues en España se incrementó el desempleo en este grupo poblacional en un $91 \%$ y en Andalucía en un $87 \%$ (Tabla 3).

El análisis de la variable género adquiere un especial interés desde la perspectiva de la relación entre crisis y mercados de trabajo (Sigüenza, 2013). En España las tasas de paro se han ido equiparando en ambos géneros como consecuencia de la crisis; así, mientras la masculina se ha incrementado de forma dramática (2006: 6,4\%; 2009: 17,6\%; 2014: $23,6 \%$ ), la femenina lo ha hecho en menor medida, lo que es debido a que partía de valores muy superiores (2006:11,3\%; 2009:18,1\%; 2014: 25,0\%); los mayores 
obstáculos que tienen que superar las mujeres para encontrar trabajo explican este hecho. En Andalucía el proceso ha sido similar, aunque con unas tasas de paro por sexo aún más alarmantes (tasas de paro masculina del 9,3\% en 2006 , del $24,1 \%$ en 2009 y del $32,7 \%$ en 2014; y tasas de paro femenina del $17,7 \%$ en 2006 , del $26,8 \%$ en 2009 y del $37,0 \%$ en 2014). No hay que olvidar que "la igualdad de género y el empoderamiento de la mujer constituyen objetivos políticos fundamentales de la Agenda 2030 para el Desarrollo Sostenible (Organización Internacional del Trabajo, 2016, p. 29).

Por su parte, la tasa de paro de la población inmigrante alcanzaba ya antes de la crisis valores más altos que la de los españoles, por lo que no es de extrañar que los efectos de la misma estén siendo especialmente duros en este colectivo. Según un estudio promovido por la Organización Internacional para las Migraciones, la tasa de desempleo de la población inmigrante $(39,1 \%)$ duplicaba a la de los nacionales (18,4\%) en 2011, (Colectivo IOÉ, 2012). Aunque en 2014 se mejoran algo estas cifras para los inmigrantes (34,5\% inmigrantes; $23,03 \%$ nacionales), no hay que obviar el hecho de que desde que se iniciara la crisis en 2007 hasta 2014 han regresado a sus países 2.440.802. extranjeros (Estadística de Variaciones Residenciales, INE). Este retorno sólo se explica porque para los que conforman este grupo social ha ido creciendo, a su vez, la probabilidad de perder el empleo, mientras se reduce la de encontrarlo (Cuadrado, Iglesias y Llorente, 2007; Medina, Herrarte y Vicéns, 2010). En un contexto como el actual en que la oferta laboral es muy superior a la demanda de trabajadores, el protagonismo de los factores diferenciadores alcanza un nivel muy superior al que existía en el periodo de crecimiento económico, lo que explica de nuevo el peor comportamiento relativo de Andalucía donde la tasa de paro de los inmigrantes alcanzó el 38,4\% en 2014.

En cuanto a la distribución territorial del desempleo, tal y como puede observarse en el mapa de la Figura 6, las tasas de paro más altas se concentran en los municipios con ciudades medias litorales, así como en las ubicadas en las principales aglomeraciones urbanas (Bahías de Cádiz y Algeciras, Sevilla y Málaga), precisamente aquellos ámbitos que en los años de crecimiento económico tuvieron una mayor dependencia de la actividad inmobiliaria. A éstas también hay que sumar algunas agrociudades del interior $y$, en menor medida, las localizadas en aglomeraciones urbanas con un vínculo aún importante a la actividad agrícola o al procesado de sus productos que, aunque en un primer momento resistieron mejor la crisis, finalmente se vieron también afectadas por la misma. Por el contrario, las que tienen unas tasas de paro menos altas, porque a pesar de que experimentaron una pérdida considerable de empleos partieron de situaciones menos dramáticas, son ciudades medias litorales con un importante desarrollo de la agricultura intensiva, junto con otras de interior con una relevante presencia de la actividad industrial, vinculada o no a la transformación de productos agrícolas.

Si se relacionan las tasas de paro con la evolución del desempleo, las conclusiones iniciales se enriquecen. En todos los municipios de más de 20.000 habitantes crece el paro 
Figura 6 - Tasas de paro, 2014

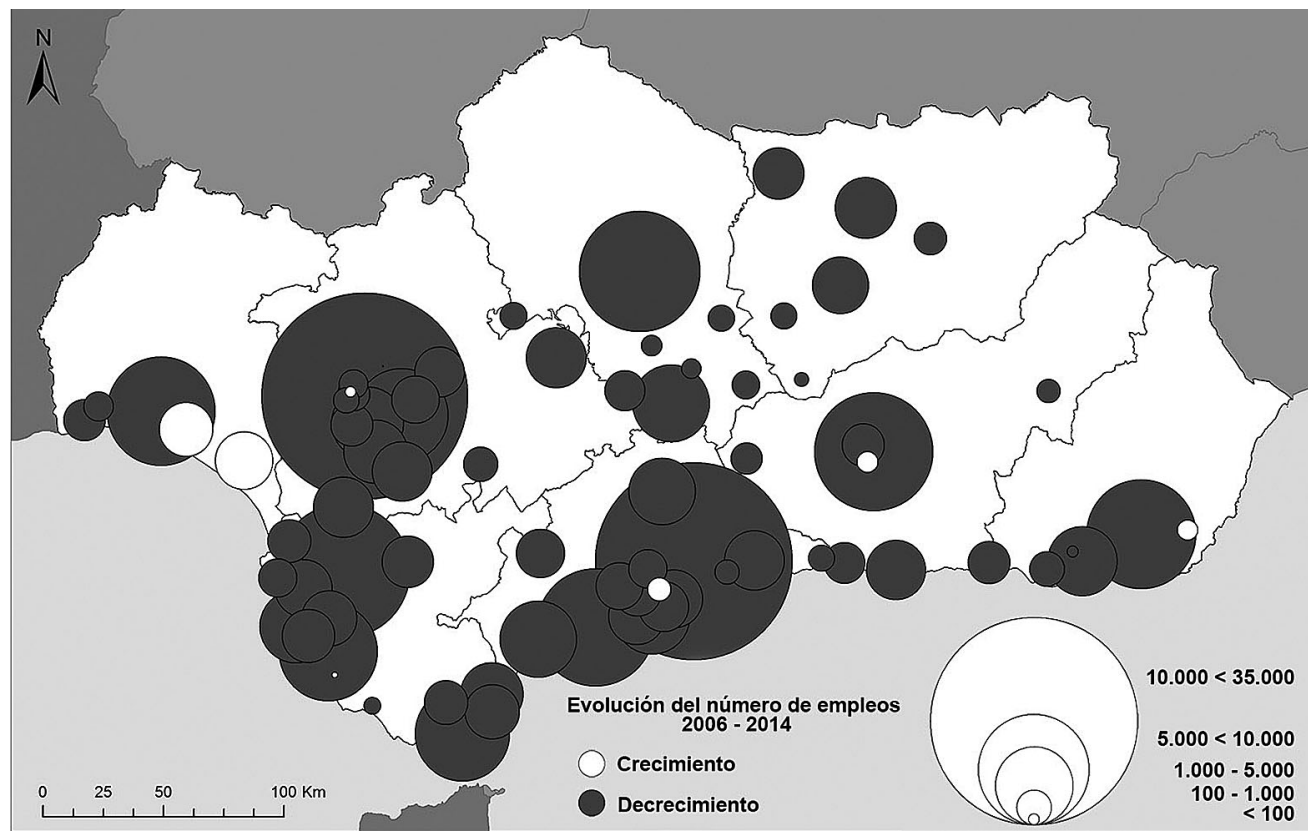

Fuente: Padrón Municipal, INE; Instituto de Estadística y Cartografía de Andalucía. Elaboración propia.

en, al menos, un $43 \%$ entre 2006 y 2014 , y en un $79 \%$ de las ciudades se duplican los valores de partida (Instituto de Estadística y Cartografía de Andalucía); estas cifras vienen a ilustrar lo dramático de la situación en muchos municipios. En algunos casos, los ámbitos territoriales con mayores crecimientos del número de parados, son también los que cuentan con mayores tasas de paro en 2014; se identifican con ciudades medias litorales y algunas aglomeraciones urbanas, poniendo así en evidencia que son estos los espacios que han sido más vulnerables a la crisis.

\section{Algunas consideraciones finales}

Las crisis han venido desempeñando un papel clave en la geografía histórica del capitalismo, por lo que el análisis de la actual no puede completarse sin tener en cuenta sus efectos en el territorio. Cómo señala Harvey (2008, 2012a, 2012b), la creciente competencia inter-capitalista junto a la fluidez con que circula espacialmente el capital financiero, impone nuevas racionalizaciones geográficas que es necesario conocer para entender 
el funcionamiento de un sistema mundo crecientemente fragmentado, inseguro y desequilibrado.

Los efectos de la crisis iniciada hace casi dos décadas se están dejando sentir con virulencia en los países de la Unión Europea, y muy especialmente en los que conforman la zona euro, poniendo en evidencia la falta de eficiencia reguladora de las instituciones comunitarias, especialmente necesaria en unos mercados fuertemente integrados. Pero resultan, además, muy preocupantes las políticas que, con la excusa de controlar los fuertes desajustes financieros, han provocado una segunda crisis. Ésta, además de contribuir a multiplicar la pérdida de empleos, precariza los contratos y está potenciando así las desigualdades sociales y los desequilibrios territoriales, reduciendo o incluso anulando los efectos de las estrategias de cohesión socio-territorial que se habían propiciado en etapas anteriores.

España es uno de los países de la Unión Europea que más puestos de trabajo está perdiendo desde que se iniciara la crisis, y aunque se han visto afectadas todas las regiones lo han hecho en mucha mayor medida aquellas consideradas periféricas que ya históricamente venían teniendo graves problemas para generar un número suficiente de empleos; tal es el caso de Andalucía. No puede extrañar, por consiguiente, que el desempleo se haya convertido en esta región en una auténtica lacra. Hay que añadir a ello el creciente deterioro de las condiciones de los nuevos contratos, de tal modo que la temporalidad, la estacionalidad y la precariedad son tres características de buena parte de los empleos que se han venido creando durante los últimos años, contribuyendo a deteriorar las condiciones de vida de un buen número de ciudadanos.

Junto a lo anterior, no hay que olvidar que la cultura neoliberal, estrechamente asociada a la pérdida de sentido ético, ha propiciado en España actitudes y comportamientos muy laxos y permisivos frente al fraude fiscal. Esto ha contribuido, por una parte, a reducir los ingresos públicos, con el hándicap que ello representa para sostener el estado del bienestar; $y$, por otra, a potenciar el crecimiento de la llamada economía sumergida y el trabajo no declarado.

En este último sentido, "el problema de la informalidad del empleo tiene sus raíces en la incapacidad de los países para crear suficientes empleos formales capaces de absorber a todas las personas que quieran trabajar. Cuando hay carencia de trabajos decentes, los trabajadores pasan al empleo informal, caracterizado generalmente por una baja productividad y salarios bajos" (Organización Internacional del Trabajo, 2016, p. 24). Pese al problema económico que la economía sumergida representa, su existencia ayuda a entender que las altas cifras de paro existentes tanto en España como en Andalucía no hayan promovido aún un estallido social generalizado.

Hay que tener en cuenta, además, que el desempleo no afecta por igual a todos los colectivos, viéndose algunos grupos sociales especialmente perjudicados:

- la evolución experimentada por los parados de larga duración está siendo extremadamente preocupante, especialmente desde que se aplican las políticas de austeridad. 
- las tasas de paro femenino se han ido equiparado a las del paro masculino como consecuencia del empeoramiento de estas últimas. El menor crecimiento relativo del paro en este colectivo no se explica por una mayor incorporación de la mujer al trabajo, sino porque el número de mujeres paradas era ya muy alto antes de la crisis;

- el paro juvenil resulta insostenible, aunque durante los últimos años se ha llegado a reducir en algunas ciudades medias vinculadas al turismo o a la agricultura, sectores que requieren de una menor cualificación de la mano de obra y que se caracterizan por una mayor estacionalidad;

- entre los efectivos considerados más vulnerables, el grupo de los inmigrantes destaca por el dramatismo que han alcanzado sus cifras de paro.

Por lo que atañe al territorio se ha podido comprobar:

- que la crisis ha afectado con distinta virulencia a las ciudades, lo que hay que poner en relación con su especialización económica y con la situación en la que se encontraba previamente su mercado de trabajo;

- las ciudades que más sufrieron la crisis desde el primer momento fueron aquellas que habían experimentado el boom inmobiliario que sostuvo parte del crecimiento económico de la fase expansiva;

- una gran parte de estas ciudades se localizan en la costa y/o forman parte de las aglomeraciones urbanas;

- los efectos de la crisis en los mercados de trabajo de las ciudades andaluzas ponen en evidencia que ha aumentado el grado de vulnerabilidad de algunas de ellas, produciéndose además nuevos desequilibrios territoriales.
Es, por consiguiente, no sólo necesario sino también urgente que las ciudades reaccionen y definan sus propias estrategias de recuperación que, aunque deban asumir las dictadas por instituciones regionales, estatales o supraestatales, se adecuen lo más posible a sus propios recursos y potencialidades, y tengan como finalidad prioritaria encontrar la forma de resolver los problemas que atañen a sus habitantes.

En definitiva, tal y como se ha venido señalando, si en la primera fase de la crisis fue el estallido de la burbuja inmobiliaria el que más contribuyó a la pérdida de empleos, las llamadas políticas de austeridad que, apoyadas por la Unión Europea, se están implementando en España están afectando muy negativamente a los colectivos y a los territorios más débiles y vulnerables. Andalucía, con problemas socioeconómicos y laborales históricamente irresueltos, se ha visto así más negativamente condicionada por la crisis que otras regiones españolas y europeas, ampliándose de nuevo la brecha que la separaba de ellas.

Se está evolucionando así en una dirección contraria a la exigible para el logro de lo que podría considerarse una sociedad justa y solidaria, que es aquélla capaz de proporcionar unas condiciones de trabajo y de vida dignos a todos los ciudadanos. Tal y como señala la OIT, "hacer del trabajo decente un pilar de la estrategia política no solo aliviaría la crisis del empleo y mejoraría las diferencias sociales sino que también contribuiría a poner al mundo económico en una senda de crecimiento mejor y más sostenible" (Organización Internacional del Trabajo, 2016, p. 9).

Por todo ello, es cada vez más necesario "estimular nuevas vías de pensamiento y 
actuación para cambiar las injustas geografías en las que vivimos" (Soja, 2014, p. 37). Se trata pues de buscar colectivamente un nuevo modelo de funcionamiento económico que, en vez de centrar la atención en el crecimiento constante y la concentración extrema de los beneficios empresariales, cree empleos suficientes y de calidad, logrando con ello una mejor distribución de la riqueza. Junto a este nuevo modelo socio-económico, basado en la utilización racional de los recursos, se requieren políticas que, respondiendo con eficacia a las necesidades de las personas: recuperen el estado del bienestar, se sustenten en una renovada cultura del territorio respetuosa con el medio ambiente y favorezcan el desarrollo de actividades económicas socialmente responsables y generadoras de empleos.

\section{Inmaculada Caravaca}

Universidad de Sevilla, Departamento de Geografía Humana. Sevillha, España.

caravaca@us.es

\section{Gema González-Romero}

Universidad de Sevilla, Departamento de Geografía Humana. Sevillha, España. gemagonzalez@us.es

\section{Notas}

(1) Según el Instituto Nacional de Estadística (INE) se consideran en paro o paradas las personas de 16 años o más que están sin trabajo y buscan activamente empleo.

(2) Teniendo en cuenta que las fuentes estadísticas disponibles sólo ofrecen datos a escala municipal, se recoge aquella referida a los municipios que cuentan con ciudades con más de 20.000 habitantes.

(3) Las tasas de empleo de la Unión Europea hacen referencia a la población entre 15 y 64 años, mientras que para España y Andalucía lo hacen para el intervalo de 16 a 64 años. 


\section{Referências}

ALBERTOS, J. M. y SÁNCHEZ, J. L. H. (coords.) (2014). Geografía de la crisis económica en España. Valencia, Universidad de Valencia.

ÁlVAREZ PERALTA, I.; LUENGO ESCALONILLA, F. y UXÓ GONZÁLEZ, J. (2013). Fracturas y crisis en Europa. Buenos Aires/Madrid, Eudeba/Clave Intelectual.

AURIOLES, J. (1995). Retos e incertidumbres económicas en la Andalucía de los 90. Ocho análisis de la Economía Andaluza. Sevilla, Instituto de Desarrollo Regional, pp. 7-39.

BELLET, C. y LLOP, J. M. (coords.) (2000). Ciudades intermedias. Urbanización y sostenibilidad. VII SEMANA DE ESTUDIOS URBANOS. Lleida, Milenio.

(2004). Miradas a otros espacios urbanos: Las ciudades intermedias. Geocrítica, v. VIII, n. 165. Disponible en: http://www.ub.es/geocrit/sn/sn-165. Acceso en: jun 2016.

BOCCARA, F.; LE HÉRON, E. y PLIHON, D. (2012). Por un sistema financiero emancipado de los mercados financieros. Vv.Aa Los economistas aterrados, Cambiar de economía. Madrid, Catarata, pp. 230-250.

BURRIEL, E. (2011). Subversion of land-use plans and the houssing bubble in Spain. Urban Research \& Practice, v. 4, n. 3, pp. 232-249.

BUSCH, K. (2014). ¿Una Europa para todos? Nueva Sociedad, n. 250, pp. 28-40. Disponible en: www. nuso.org. Acceso en: ago 2016.

CAMAGNI, R. y SALONE, C. (1993). Network urban structures in Northern Italy: elements for a theoretical framework. Urban Studies, v. 30, n. 6, pp. 1053-1064.

CAPEL, H. (2003). Una mirada histórica sobre los estudios de redes de ciudades y sistemas urbanos. Geotropico, v. 1, n. 1. Disponible en: http://www.geotopico.org. Acceso en: mar 2015.

CARAVACA, I. (2014). Los territorios en la crisis. Ciudad y Territorio. Estudios Territoriales, v. XLVI, n. 182 , pp. 607-624.

CARAVACA, I.; GONZÁLEZ, G.; MENDOZA, A. y SILVA, R. (2009). Dinamismo, innovación y desarrollo en ciudades pequeñas y medias de Andalucía. Sevilla, Consejo Económico y Social de Andalucía (Premio de Investigación 2008).

CASTELLS, M. (1995). La ciudad informacional. Tecnologías de la información, reestructuración económica y el proceso urbano-regional. Madrid, Alianza Editorial.

(1996). The rise of the Network Society. Blakwell, Massachusetss-Oxford.

CASTELLS, M. y HALL, P. (dirs.) (1992). Andalucía: innovación tecnológica y desarrollo económico. Madri, Espasa Calpe.

COLECTIVO IOÉ (2012). Impactos de la crisis sobre la población inmigrante. Disponible en: http:// www.colectivoioe.org/uploads/0bae582aa3b0842a9eaf50cde16f4f97d9527bcb.pdf. Acceso en: jun 2014.

COMISIÓN EUROPEA (1999). Estrategia Territorial Europea. Hacia un desarrollo equilibrado y sostenible del territorio de la Unión Europea. Luxemburgo, Comisión Europea.

COMISIÓN EUROPEA (1999). Primer Informe de Cohesión Territorial. Bruselas, Comisión Europea. 
COMISIÓN EUROPEA (2000). Study Programme on European Spatial Planning. Final Report. Bruselas/

Estocolmo, Comisión Europea.

(2000). Segundo Informe de Cohesión Territorial. Bruselas, Comisión Europea.

(2004). Tercer Informe Intermedio de Cohesión Territorial. Bruselas, Comisión Europea.

CONSEJERÍA DE OBRA PÚBLICAS Y TRANSPORTE (2007). Plan de Ordenación del Territorio de Andalucía. Sevilla, Junta de Andalucía. Disponible en: http://www.juntadeandalucia.es/medioambiente/ portal_web/ot_urbanismo/ordenacion_territorio/pota/pota_titulo1.pdf. Acceso en: ago 2016.

CORPATAUX, J.; CREVOISIER, O. y THEURILLAT, T. (2009). The expansión of the finance industry and its impacto in the economy: a territorial aproach base on Swiss pension funds. Economic Geography, v. 85, n. 3, pp. 313-334.

CUADRADO, J. R.; IGLESIAS, C. y LLORENTE, R. (2007). Inmigración y mercado de trabajo. Madrid, Fundación BBVA.

DAHER, A. (2004). "Riesgo país versus riesgo región: Santiago en el Mercosur". In: DE MATTOS, C. et al. (eds.). Santiago en la globalización: ¿una nueva ciudad? Santiago de Chile, Ediciones SUR/Eure, pp. 85-113. Disponible en: http://www.sitiosur.cl/r.php?id=17. Acceso en: jul 2015.

(2013). El sector inmobiliario y las crisis económicas. Eure Revista Latinoamericana de Estudios Urbano-Regionales, v. 39, n. 118, pp. 47-76.

DELGAdo CABEZA, M. (1981). Dependencia y marginación de la economía Andaluza. Córdoba, Publicaciones del Monte de Piedad y Caja de Ahorros de Córdoba.

(1996). Integración y reestructuración desde la periferia europea. Eure Revista Latinoamericana de Estudios Urbano Regionales, v. XXII, n. 66, pp. 7-25.

(2006). Economía, Territorio y Desigualdades Regionales. Revista de Estudios Regionales, n. 75, pp. 93-128.

DELGADO CABEZA, M. y SÁNCHEZ FERNÁNDEZ, J. (1999). Las desigualdades territoriales en el Estado español 1955-1995. Eure Revista Latinoamericana de Estudios Urbano Regionales, v. XXV, n. 75, pp. 41-62.

DÉVOLUY, M. et al. (2012). La política económica en Europa. Vv.Aa Los Economistas aterrados, Cambiar de Economía. Madri, Catarata, pp. 49-74.

ETXZARRETA, M. (2009). Algunos aspectos fundamentales para entender la crisis. Gaceta Sindical. Reflexión y debate. Fundación 10 de Mayo, no 12, pp. 39-64. Disponible en: http://www.ccoo.es/ comunes/recursos/1/pub12430_n_12._La_crisis_economica_y_el_nuevo_escenario_mundial. pdf. Acceso en: jun 2013.

FERNÁNDEZ DURÁN, R. (2011). La quiebra del capitalismo global: 2000-2030. Bilbao, Virus Editorial.

GORZ, A. (1995). Metamorfosis del trabajo. Madri, Editorial Sistema.

HARVEY, D. (2008). La condición de la posmodernidad. Buenos Aires/Madrid, Amorrurto.

(2012a). El enigma del capital y las crisis del capitalismo. Madri, Akal.

(2012b). "Las raíces urbanas de las crisis financieras". In: BELIL, M.; BORJA, J. y CORTI, M. (eds.). Ciudades, una ecuación imposible. Icaria, Barcelona.

HUSSON, M. (2009). Capitalismo puro. Madri, Maia. 
INTERMÓN OXFAM (2012). Crisis, desigualdad y pobreza. Aprendizaje desde el mundo en desarrollo ante los recortes sociales en España. Disponible en: http://www.oxfamintermon.org/es/ informate/publicaciones/estudios. Acceso en: out 2012.

LAVAL, C. y DARDOT, P. (2013). La nueva razón del mundo. Ensayo sobre la sociedad neoliberal. Barcelona, Gedisa.

LEE, N.; MORRIS, K. y JONES, A. (2009). How UK cities can respond and drive recovery. The Work Foundation, LEED Programme, Londres.

LÓPEZ, I. y RODRÍGUEZ, E. (2010). Fin de ciclo. Financiarización. Territorio y sociedad de propietarios en la onda larga del capitalismo hispano (1959-2010). Madri, Traficantes de Sueños.

LORDON, F. (2012).La pavorosa pasividad de la re-regulación financiera. Los economistas aterrados, Cambiar de economía. Madri, Catarata, pp. 251-281.

MARTIN, R. y SIMMIE, J. (2008). Path dependence and local innovation systems in city-regions. Innovation Management Policy \& Practice, n. 10, pp. 183-196.

MAYOR ZARAGOZA, F. (2011). Traspasar los límites de lo posible. Vv.Aa, Reacciona. Madrid, Aguilar.

MEDINA, E.; HERARTE, A. y VICENS, J. (2010). Inmigración y desempleo en España: Impacto de la crisis económica. Información Comercial Española, pp. 37-48.

MÉNDEZ, R. (2002). Innovación y desarrollo territorial: algunos debates teóricos recientes. Eure, Revista Latinoamericana de Estudios Urbanos Regionales, v. 28, n. 84, pp. 63-84.

(2013a). Las escalas de la crisis. Ciudades y desempleo en España. Fundación 1o de Mayo. Disponible en: WWW.1MAYO.CCOO.ES. Acceso en: jan 2014.

(2013b). Crisis económica, vulnerabilidad urbana y desempleo en España. Ciudad y Territorio Estudios Territoriales, v. XLV, n. 178, pp. 1-19.

(2014). “Crisis económica y reconfiguraciones territoriales". In: ALBERTOS, J. M. y SÁNCHEZ HERNÁNDEZ, J. L. (coords.). Geografía de la crisis económica en España. Valencia, Universidad de Valencia, pp. 17-38.

MÉNDEZ, R.; ABAD, L. y ECHAVES, C. (2015). Atlas de la crisis. Impactos socioeconómicos y territorios vulnerables en España. Valencia, Tirant Lo Blanc. Colección Crónica.

MORIN, E. (2011). La Vía. Para el futuro de la humanidad. Barcelona, Paidós Estado y Sociedad.

NAREDO, J. M. (2009). La cara oculta de la crisis. El fin del boom inmobiliario y sus consecuencias. Revista de Economía Crítica, n. 7, pp. 313-340.

(2010). El modelo inmobiliario español y sus consecuencias. Urbanismo, Democracia y Mercado: una experiencia española (1970-2010). Madri, ETS Arquitectura y Casa de Velázquez.

ORGANIZACIÓN INTERNACIONAL DEL TRABAJO (2016). Perspectivas sociales y del empleo en el mundo. Tendencias 2016. Genebra, OIT. Disponible en: http://www.ilo.org/wcmsp5/groups/public/--dgreports/---dcomm/---publ/documents/publication/wcms_443505.pdf. Acceso en: set 2016.

OXFAM INTERMON (2013). La trampa de la austeridad. El verdadero coste de la desigualdad en Europa. Disponible en: http://www.oxfamintermon.org/es/informate/publicaciones/estudios. Acceso en: out 2013.

PAULAIS, T. (2009). Local governments and the financial crisis: an analysis. Washington, Cities Alliance. 
ROCHA, F. (2012). La crisis económica y sus efectos sobre el empleo en España. Gaceta Sindical, n. 19, pp. 67-90. Disponible en: http://www.ccoo.es/comunes/recursos/1/pub86043_n_19._Las_ politicas_de_recortes_evaluacion_y_danos.pdf. Acceso en: dez 2012.

ROCHA, F. y ARAGÓN, J. (2012). La crisis económica y sus efectos sobre el empleo. Colección Informes, n. 55, Fundación 1o de Mayo. Disponible en: http://www.1mayo.ccoo.es/nova/files/1018/ Informe55.pdf. Acceso en: jul 2014.

ROCHA SÁNCHEZ, F.y NEGUERUELA CORTÉS, E. (2014). El mercado de trabajo en España en 2013. ¿Hacia una recuperación frágil y socialmente injusta de la crisis? Colección Informes, n. 87, Fundación 1o de Mayo. Disponible en: http://www.1mayo.ccoo.es/nova/files/1018/Informe87. pdf. Acceso en: dez 2014.

RODRÍGUEZ, E. y LÓPEZ, I. (2011). Del auge al colapso. El modelo financiero-inmobiliario de la economía española (1995-2010). Economía Crítica, n. 12, pp. 39-64.

ROMERO, J. (2010). Construcción residencial y gobierno del territorio en España. De la burbuja especulativa a la recesión. Causas y consecuencias. Cuadernos Geográficos, n. 47, pp. 17-46.

SALOM, J. y ALBERTOS, J. M. (2009). Redes socioinstitucionales, estrategias de innovación y desarrollo territorial en España. Publicaciones de la Universidad de Valencia, Valencia.

SASSEN, S. (2015). Expulsiones, brutalidad y complejidad en la economía global. Buenos Aires/Móstoles (Madrid), Katz.

SIGÜENZA, A. (2013). Desempleo y mujer en la crisis. Secretaría de Acción Social de la Confederación Nacional del Trabajo. Disponible en: http://cnt.es/sites/default/files/CNT_Desemplo_y_Mujer_ en_la_crisis.pdf. Acceso en: nov 2013.

SOJA, E. W. (2014). En busca de la justicia espacial. Valencia, Tirant Humanidades.

SOTO, P. (2010). Cities at the economic crisis. A survey on the impact of the economic crisis and the responses of URBACT /I cities. Bruxelas, Unión Europea, Fondo Europeo de Desarrollo Regional.

STERDYNIAK (2012). ¿Que política económica? Muertes y resurrecciones del keynesianismo. Los economistas aterrados, Cambiar de economía, pp. 21-48. Madri, Catarata.

TORRES LÓPEZ, J. (2011). Contra la crisis, otra economía y otro modo de vivir. Móstoles (Madrid), Hoac.

VELTZ, P. (1996). Mondalisation, villes et territoires. L'Économie d'archipel. Paris, P.U.F.

WAKERMAN, G. (2011). Vers une nouvelle mondalisation. Paris, Ellipses.

VVAA (2012). Los economistas aterrados. Cambiar de economía. Madri, Catarata.

ZOIDO, F. (1995). Sistema de asentamientos, ciudades medias y aglomeraciones urbanas de Andalucía. Revista Situación (BBV), n. 3, pp. 149-162.

Texto recebido em 25/set/2016 Texto aprovado em 2/dez/2016 
